\title{
Efeito da adição de probióticos sobre as características de queijo prato com reduzido teor de gordura fabricado com fibras e lactato de potássio
}

\author{
Effect of the addition of probiotics on the characteristics of reduced-fat \\ "prato" cheese manufactured with fibers and potassium lactate
}

Alexandre José CICHOSKI ${ }^{1 \star}$, Cássia CUNICO², Marco DI LUCCIO ${ }^{1}$, João Luiz ZITKOSKI², Ricardo Toledo de CARVALHO²

\begin{abstract}
Resumo
Leite pasteurizado com $1,3 \%$ de gordura foi utilizado na elaboração de queijo prato, no qual foi adicionado cultura probiótica de Lactobacillus rhamnosus e fibras, com substituição parcial do cloreto de sódio por solução de lactato de potássio a $60 \%$. O objetivo do trabalho foi acompanhar o efeito da cultura probiótica adicionada no queijo prato fabricado com fibras e com substituição de cloreto de sódio por lactato de potássio, durante o período de 90 dias de armazenamento, a $6{ }^{\circ} \mathrm{C}$. As análises físico-químicas e microbiológicas foram realizadas no queijo antes de ser embalado a vácuo e no 15, 30, 45, 60, 75 e 90 dia de armazenamento. O queijo com cultura probiótica, em todos os dias em que foi analisado, caracterizou-se por apresentar maior contagem de bactérias lácticas, valor de $\mathrm{pH}$, teor de lactose e menor valor de acidez em relação ao queijo que não continha cultura probiótica.
\end{abstract}

Palavras-chave: queijo prato; probiótico; lactato de potássio; fibras.

\begin{abstract}
Pasteurized milk with $1.3 \%$ fat was used in the preparation of "prato" cheese, with the addition of the probiotic microorganism Lactobacillus rhamnosus, fibers, and partial substitution of sodium chloride by a $60 \%$ potassium lactate solution. The aim of this work was to follow the development of lactic bacteria and the evolution of $\mathrm{pH}$, lactose content and acidity during storage for 90 days, at $6{ }^{\circ} \mathrm{C}$, since not much information about the addition of such a probiotic in "prato" cheese is available. Cheese was prepared by the conventional method, followed by vacuum packing and storage. Analyses were carried out immediately after preparation and after 15, 30, 45, 60, 75 and 90 days of storage. The cheese formulated with the probiotic culture presented higher counts of lactic bacteria, higher $\mathrm{pH}$ and lactose content, but lower acidity than the cheese prepared without the probiotic.
\end{abstract}

Keyword: cheese; potassium lactate; probiotics; fibers.

\section{Introdução}

No setor lácteo, os alimentos funcionais já são uma realidade e muitas empresas de alimentos desenvolvem suas linhas de produtos tendo a promoção da saúde como principal objetivo. Isso se deve ao fato de que os consumidores estão cada vez mais preocupados com a saúde, e também porque os alimentos funcionais constituem-se hoje, como prioridade de pesquisa em todo o mundo, com a finalidade de elucidar as propriedades e os efeitos benéficos que estes produtos podem proporcionar à saúde e ao bem-estar (BELCHIOR, 2004).

Os probióticos são descritos como culturas de uma única espécie ou de várias espécies de microrganismos, que quando utilizadas por animais ou pelo homem, trazem benefícios à saúde, promovendo melhora nas características da microflora intestinal natural. Os produtos com probióticos representam um forte nicho entre os alimentos funcionais, e muitas pesquisas são desenvolvidas com o objetivo de incorporar estes organismos aos alimentos (STANTON et al., 2001). Os probióticos mais comumente estudados e utilizados como suplemento em alimentos pertencem aos gêneros Lactobacillus e Bifidobacterium. Um produto para ser considerado alimento com probiótico deve apresentar contagem de probióticos maior ou igual a $1 \times 10^{7}$ células viáveis/g ou $\mathrm{mL}$ do produto. Todavia, a quantidade mínima requerida e o período ideal para a administração dos probióticos, para se obter efeitos benéficos para a saúde, não estão claros, já que o número varia de acordo com a espécie de microrganismo e com o tipo de alimento (ISOLAURI et al., 2001; OHR, 2002). 
Estudos mostraram que o baixo $\mathrm{pH}$ dos leites fermentados pode ser inadequado para a sobrevivência de certas espécies de bactérias probióticas, e sugerem o queijo como veículo mais adequado para estas bactérias. O queijo, além de possuir maior $\mathrm{pH}$ que os leites fermentados, possui também uma matriz sólida, a qual pode proteger essas bactérias com maior eficiência que o ambiente fluido do leite, durante o período de estocagem e também durante o trânsito no organismo humano (KASIMOGLU; GÖNCÜOGLU; AKGÜN, 2004; SONGISEPP et al., 2004; ZALAZAR et al., 2004).

Queijos Cheddar, Gouda, Cottage, Crescenza e cremoso foram testados como veículos para cepas probióticas de Lactobacillus e de Bifidobacterium, revelando-se apropriados (BURITI, 2005).

Os probióticos utilizados em alimentos devem crescer e sobreviver aos processos de elaboração, maturação e estocagem do produto, bem como não afetar negativamente a qualidade do produto e ser seguro à saúde do consumidor (SALMINEN; OUWEHAND; ISOLAURI, 1998; ISOLAURI et al., 2001; STANTON et al., 2001; ZALAZAR et al., 2004).

A sobrevivência das bactérias probióticas em queijos frescos é maior quando comparada aos queijos maturados. Essa maior sobrevivência estaria relacionada ao menor tempo de armazenamento dos queijos frescos, ao menor teor de sal e ao maior teor de umidade e atividade de água, que não limitariam a multiplicação do probiótico (BURITI, 2005).

Poucos estudos científicos relatam a adição de probióticos do gênero Lactobacillus em queijos maturados (SONGISEPP et al., 2004). O Lactobacillus rhamnosus faz parte da flora intestinal saudável do homem (GORBACH, 2002) e seus benefícios em relação à prevenção de distúrbios intestinais têm sido amplamente estudados. Quando comparado com outros microrganismos probióticos, mostrou maior tolerância às condições do trato gastrointestinal e melhor sobrevivência, quando adicionado em alimentos funcionais (LANDERSJÖ et al., 2002). O Lactobacillus rhamnosus GG é capaz de aderir à mucosa intestinal in vivo e ali permanecer aderido por mais de uma semana após a descontinuidade da sua administração via oral (ALANDER et al., 1999).

Fibras alimentares são partes de plantas ou carboidratos análogos que são resistentes à digestão e absorção no intestino delgado humano, e são completamente ou parcialmente fermentadas no intestino grosso, fornecendo energia principalmente para o crescimento bacteriano. Dividem-se em fibras solúveis (pectinas, $\beta$-glucana, gomas, inulina e polidextrose) e fibras insolúveis (celulose, hemicelulose, lignina, cutina, suberina, ceras de plantas, quitina e quitosana) (VAN DENDER; BOSI; CONRADO, 2005). A mudança de hábitos alimentares na vida das pessoas é difícil, pois na maioria das vezes isso significa mudança em seu estilo vida. Assim, fibras que auxiliam na manutenção da saúde e que são encontradas em frutas e vegetais não são consumidas (OHR, 2002; VAN DENDER; BOSI; CONRADO, 2005).

Dentre as fibras alimentares disponíveis no mercado, a inulina é um exemplo de oligossacarídeo que tem tido aceitação crescente, uma vez que não é digerida nem absorvida no intes- tino delgado, e conseqüentemente chega ao cólon como uma molécula intacta, agindo como substrato fermentável para bifidobactérias e lactobacilos. Por funcionar como um prebiótico, a inulina está associada às melhorias nos sistemas gastrointestinal e imunológico (OHR, 2002; TUNGLAND, 2005).

O consumo excessivo de cloreto de sódio tem se tornado um grande problema de saúde pública; em decorrência, muitos estudos de agências governamentais e associações médicas indicam forte correlação entre o consumo de cloreto de sódio e a hipertensão arterial, bem como outras doenças cardiovasculares e renais (KATSIARI et al., 1998; KAPLAN, 2000).

Este trabalho teve como objetivo acompanhar o efeito da adição de cultura probiótica, constituída de Lactobacillus rhaminosus, em queijo prato fabricado com fibras e com substituição de cloreto de sódio por lactato de potássio, durante o período de 90 dias de armazenamento, a $6{ }^{\circ} \mathrm{C}$.

\section{Material e métodos}

\subsection{Fabricação dos queijos}

Foram fabricados dois tipos de queijo na planta piloto da Usina Corlac S.A., na cidade de Erechim (RS), sendo um considerado teste e outro padrão. Em ambos foi utilizado leite pasteurizado a $75^{\circ} \mathrm{C}$ durante 15 segundos com $1,3 \%$ de gordura. $\mathrm{O}$ primeiro a ser fabricado foi o queijo teste e os ingredientes foram adicionados no tanque de aço inox da seguinte maneira: 150 litros de leite, $60 \mathrm{~mL}$ de solução de cloreto de cálcio a $40 \%$ (Chr Hansen), $6 \mathrm{~mL}$ de corante de urucum (Chr Hansen), $450 \mathrm{~g}$ de concentrado protéico de leite, $1,7 \mathrm{~g}$ de coagulante quimosina produzido por fermentação a partir do Aspergillus niger var. awamori (Chymax da Chr Hansen), $300 \mathrm{~g}$ de inulina (Orafti), e somente no queijo teste foi adicionado $6,25 \mathrm{U}$ de cultura probiótica Lactobacillus rhamnosus (Rhodia). Não foi utilizada a cultura láctica na fabricação dos queijos, pois o objetivo foi acompanhar o que aconteceria a um queijo no qual fosse adicionada cultura probiótica, sendo esse também o motivo do armazenamento durante 90 dias. O concentrado protéico de leite foi utilizado para auxiliar na textura do queijo, uma vez que o leite utilizado foi parcialmente desnatado.

A coagulação ocorreu a $35{ }^{\circ} \mathrm{C}$ e efetuou-se o corte da coalhada após 40 minutos da adição do coagulante. Aqueceu-se a massa a $45^{\circ} \mathrm{C}$ e deixou-se em repouso por alguns minutos. Depositada a massa no fundo do tanque, procedeu-se à retirada do soro e posterior lavagem da mesma. Obtida a massa, procedeu-se à pesagem para calcular a quantidade de sal e lactato de potássio a serem adicionados. Foram adicionados nas massas dos dois queijos $135 \mathrm{~g}$ de cloreto de sódio (Salsul) e $135 \mathrm{~g}$ de solução de lactato de potássio a 60\% (Purasal, Purac). Após a salga, as massas foram colocadas nas fôrmas, as quais foram levadas à prensa hidráulica para a primeira prensagem a $20 \mathrm{lb} / \mathrm{pol}^{2}$ durante 60 minutos. Transcorrido o tempo, os queijos foram invertidos dentro das fôrmas e trocaram-se as mesmas de lugar na prensa, então iniciou-se a segunda prensagem a $30 \mathrm{lb} / \mathrm{pol}^{2}$ durante 120 minutos. No final da prensagem os queijos foram embalados a vácuo e levados à câmara de maturação, onde permaneceram durante 90 dias, a $6{ }^{\circ} \mathrm{C}$ e $85 \%$ UR. 
Salienta-se que o queijo teste e o queijo padrão não foram fabricados concomitantemente. Após 5 horas de fabricado o queijo teste, iniciou-se a fabricação do queijo padrão. Durante todo esse tempo, os 150 litros de leite empregados na fabricação desse queijo permaneceram dentro de três tarros com capacidade de 50 litros cada, à temperatura de $20^{\circ} \mathrm{C}$.

\subsection{Amostragem}

Foi caracterizado o leite empregado na elaboração do queijo teste, pela equipe do laboratório da empresa, 30 minutos antes do início da fabricação, em relação a acidez Dornic, pH, crioscopia, densidade, proteína, gordura, extrato seco total e bactérias ácido lácticas. Caracterizou-se também o leite empregado na fabricação do queijo padrão após 5 horas a $20^{\circ} \mathrm{C}$, antes de ser colocado no tanque.

As análises microbiológicas e físico-químicas nos queijos foram realizadas antes dos mesmos serem embalados a vácuo (logo depois de elaborados) e no 15, 30, 45, 60, 75 e $90^{\circ}$ dia de armazenamento.

\subsection{Análise microbiológica}

\section{Bactérias ácido lácticas}

O número de colônias das bactérias ácido lácticas foi determinado utilizando-se o método de plaqueamento em profundidade, com sobrecamada em Agar Man, Rogosa \& Sharpe (MRS). As placas foram incubadas durante 72 horas à temperatura de $30{ }^{\circ} \mathrm{C}$ (SILVA; JUNQUEIRA; SILVEIRA, 1997).

\subsection{Análises físico-químicas}

\section{Umidade}

Foi determinada conforme metodologia descrita pelo IAL (2005).

\section{Atividade de água $\left(a_{w}\right)$}

Foi determinada à temperatura de $25^{\circ} \mathrm{C}\left( \pm 4^{\circ} \mathrm{C}\right)$, utilizandose o equipamento Aqua Lab, modelo CX-2 Water Activity System, seguindo metodologia descrita em seu manual.

$p H$

Foi determinado pelo método potenciométrico, utilizandose potenciômetro da marca Digimed, calibrado com soluções tampão em pH 4 - 7 conforme metodologia descrita pelo IAL (2005).

\section{Determinação da lactose}

A lactose foi determinada conforme metodologia descrita pela FIL-IDF, 28 - A (1974). Os miligramas de óxido de cobre I obtidos da filtração foram convertidos em gramas de lactose anidra mediante utilização de tabelas especiais de conversão.

\section{Determinação da acidez}

A acidez foi determinada por titulação conforme metodologia descrita por IAL (2005). O resultado foi expresso em porcentagem de compostos com caráter ácido expresso como ácido láctico.

\section{Determinação da densidade a $15^{\circ} \mathrm{C}$}

Foi determinada conforme metodologia descrita pelo IAL (2005).

\section{Determinação da proteína}

Foi determinada pelo método do formol conforme metodologia descrita pelo IAL (2005).

\section{Determinação da gordura}

Foi determinada utilizando-se o lactobutirômetro de Gerber, conforme metodologia descrita pelo IAL (2005).

\section{Determinação do extrato seco}

Foi determinado pelo método indireto usando a fórmula de Furtado, em que: \% ES = 1,2 x Gor. + 0,25 x D + 0,25, conforme metodologia descrita pelo IAL (2005).

\section{Determinação do ponto crioscópico}

Foi determinado de forma eletrônica utilizando-se o aparelho ITR modelo MK540 e seguindo metodologia descrita em seu manual.

\section{Análise estatística}

Todas as análises microbiológicas e físico-químicas foram realizadas em triplicata verdadeira, e os resultados foram analisados estatisticamente através de cálculos de média, desvio padrão, análise de variância e teste de Tukey com significância ao nível de $5 \%(\mathrm{p}<0,05)$. Como cada tipo de queijo foi fabricado apenas uma vez, os dados serão apresentados como resultados preliminares (CAMPOS, 1983).

\section{Resultados e discussão}

Os parâmetros físico-químicos e a contagem inicial das bactérias ácido lácticas do leite empregado na fabricação dos queijos teste e padrão encontram-se na Tabela 1.

O teor de gordura caracterizou os leites empregados na fabricação dos queijos teste e padrão como leite pasteurizado tipo C semidesnatado (Tabela 1). Ambos os leites apresentaram valores de acidez Dornic, de crioscopicidade e densidade dentro dos critérios de identidade e qualidade de leite pasteurizado tipo C semidesnatado (BRASIL, 2002). A análise das bactérias ácido lácticas não é exigida nos critérios de identidade e qualidade do leite, mas foi realizada com o objetivo de se ter uma idéia da contagem inicial, uma vez que se utilizou somente cultura probiótica no queijo teste, já no queijo padrão nenhum tipo de cultura láctea foi utilizada. O leite empregado na fabricação 
do queijo teste apresentou maior valor de $\mathrm{pH}$ e menor valor de acidez Dornic e desenvolvimento de colônias de bactérias ácido lácticas, do que o leite utilizado na fabricação do queijo padrão (Tabela 1).

Os resultados preliminares do desenvolvimento das colônias de bactérias ácido lácticas nos queijos prato padrão e teste, antes de serem embalados a vácuo e durante o armazenamento de 90 dias, a $6{ }^{\circ} \mathrm{C}( \pm 1)$ e UR 85\%, encontram-se na Figura 1.

$\mathrm{O}$ queijo teste apresentou resultado preliminar médio de umidade de $50,86 \%( \pm 0,32)$ e $a_{w} 0,990( \pm 0,01)$, e o queijo padrão de $50,59 \%( \pm 0,22)$ e $a_{w} 0,993( \pm 0,01)$. Embora esses resultados preliminares tenham sido semelhantes, o número de colônias das bactérias ácido lácticas no queijo teste foi maior e significativo pelo teste de Tukey $(\mathrm{p}<0,05)$, em todos os dias analisados, quando comparado ao número de colônias encontradas no queijo padrão (Figura 1). O tempo transcorrido entre a fabricação do queijo teste e o padrão (5 horas) influenciou no número de colônias de bactérias ácido lácticas encontrado no queijo padrão. Isso ocorreu porque durante esse período de tempo o leite empregado na fabricação do queijo padrão permaneceu à temperatura de $20^{\circ} \mathrm{C}$, a qual favoreceu o desenvolvimento das bactérias ácido lácticas, uma vez que inicialmente o leite

Tabela 1. Parâmetros físico-químicos e microbiológicos dos leites empregados na fabricação dos queijos teste e padrão.

\begin{tabular}{lcc}
\hline \multicolumn{1}{c}{$\begin{array}{c}\text { Parâmetros } \\
\text { físico-químicos }\end{array}$} & $\begin{array}{c}\text { Leite empregado } \\
\text { no queijo teste }\end{array}$ & $\begin{array}{c}\text { Leite empregado } \\
\text { no queijo padrão }\end{array}$ \\
\hline Acidez Dornic & $14^{\circ} \mathrm{D}$ & $15^{\circ} \mathrm{D}$ \\
$\mathrm{pH}$ & 6,68 & 6,40 \\
Crioscopia & $-0,533^{\circ} \mathrm{H}$ & $-0,533{ }^{\circ} \mathrm{H}$ \\
Densidade a $15^{\circ} \mathrm{C}$ & $1031 \mathrm{~g} \cdot \mathrm{L}^{-1}$ & $1031 \mathrm{~g} \cdot \mathrm{L}^{-1}$ \\
Proteína & $2,8 \%\left({\left.\mathrm{~m} \cdot \mathrm{v}^{-1}\right)}^{-1}\right.$ & $2,8 \%\left(\mathrm{~m} \cdot \mathrm{v}^{-1}\right)$ \\
Gordura & $1,34 \%\left(\mathrm{~m} \cdot \mathrm{v}^{-1}\right)$ & $1,34 \%\left(\mathrm{~m} \cdot \mathrm{v}^{-1}\right)$ \\
Extrato seco total & $9,61 \%\left(\mathrm{~m} \cdot \mathrm{v}^{-1}\right)$ & $9,61 \%\left(\mathrm{~m} \cdot \mathrm{v}^{-1}\right)$ \\
$\quad$ Parâmetro microbiológico & & \\
Bactérias ácido lácticas & $5,30 \log \mathrm{UFC} \cdot \mathrm{g}^{-1}$ & $7,30 \mathrm{log} \mathrm{UFC} \cdot \mathrm{g}^{-1}$ \\
\hline
\end{tabular}

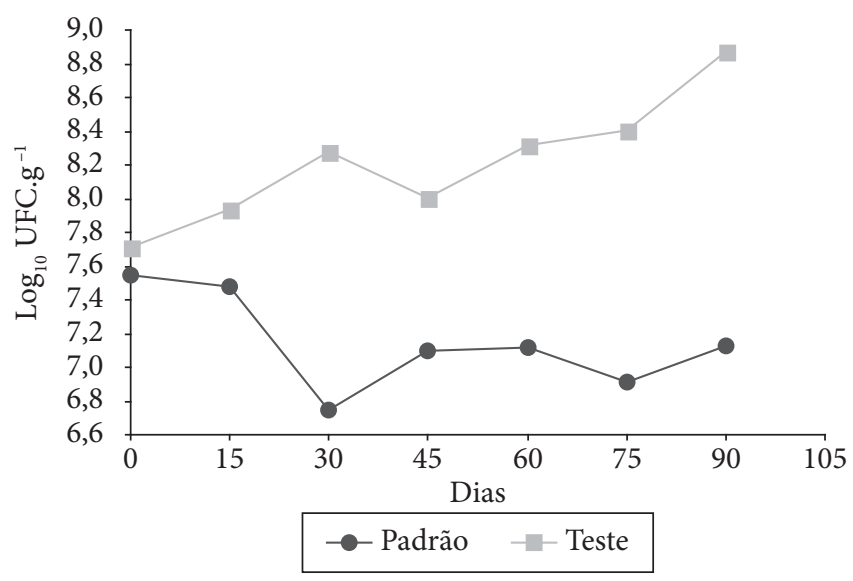

Figura 1. Resultados preliminares do desenvolvimento das colônias de bactérias ácido lácticas em queijo prato padrão e teste, antes de ser embalado a vácuo e durante 90 dias de armazenamento, a $6{ }^{\circ} \mathrm{C}( \pm 1)$ e UR $85 \%$. apresentava 5,30 log UFC.g ${ }^{-1}$ e depois passou para 7,40 log UFC.g ${ }^{-1}$ (Tabela 1).

A contagem inicial de culturas lácteas adicionadas em queijo prato varia entre $10^{8}$ a $10^{9} \mathrm{UFC}^{-1}{ }^{-1}$ (VARNAM; SUTHERLAND, 1995; FURTADO, 2002). O queijo teste, do $30^{\circ}$ dia de armazenamento em diante, apresentou contagem de bactérias ácido lácticas igual a $10^{8} \mathrm{UFC}_{\text {. }}{ }^{-1}$ (Figura 1), enquanto que no queijo padrão em todos os dias analisados isto nunca ocorreu.

O queijo prato é classificado como de média umidade pois apresenta valores entre 36 a 45,9\% (BRASIL, 1997). O queijo teste apresentou valor de umidade de 50,86\%, sendo este superior ao limite máximo estabelecido para queijo prato, pelo regulamento técnico de identidade e qualidade. Segundo BANKS (2004), a redução no conteúdo de gordura do leite resulta num significante aumento de $\mathrm{pH}$, umidade e conteúdo de proteína no queijo elaborado com esse produto.

O queijo prato elaborado com leite contendo 3,5\% de gordura, após um dia de maturação, apresentou valor de umidade de $45,80 \%$ e a 0,97 (DA SILVEIRA; ABREU, 2003), enquanto que o elaborado com leite contendo $1,9 \%$ de gordura e embalado a vácuo, apresentou valor de umidade de 50,49\% e a 0,98 (SILVA et al., 2005). O queijo teste foi elaborado com leite contendo menor conteúdo de gordura (1,3\%), conseqüentemente, apresentou maior teor de umidade $(50,89 \%)$ e valor de $\mathrm{a}_{\mathrm{w}} 0,99$.

Os resultados preliminares de $\mathrm{pH}$ nos queijos padrão e teste determinados antes de serem embalados a vácuo, e nos queijos durante os 90 dias de armazenamento, a $6{ }^{\circ} \mathrm{C}( \pm 1)$ e UR $85 \%$, são apresentados na Figura 2.

Os resultados preliminares de $\mathrm{pH}$ apresentados pelo queijo teste foram maiores do que os encontrados no queijo padrão em todos os dias analisados, apresentando diferenças significativas pelo teste de Tukey $(\mathrm{p}<0,05)$. Os fatores que estariam influenciando esses resultados seriam: a fabricação dos queijos não ocorrer ao mesmo tempo e a adição da cultura probiótica.

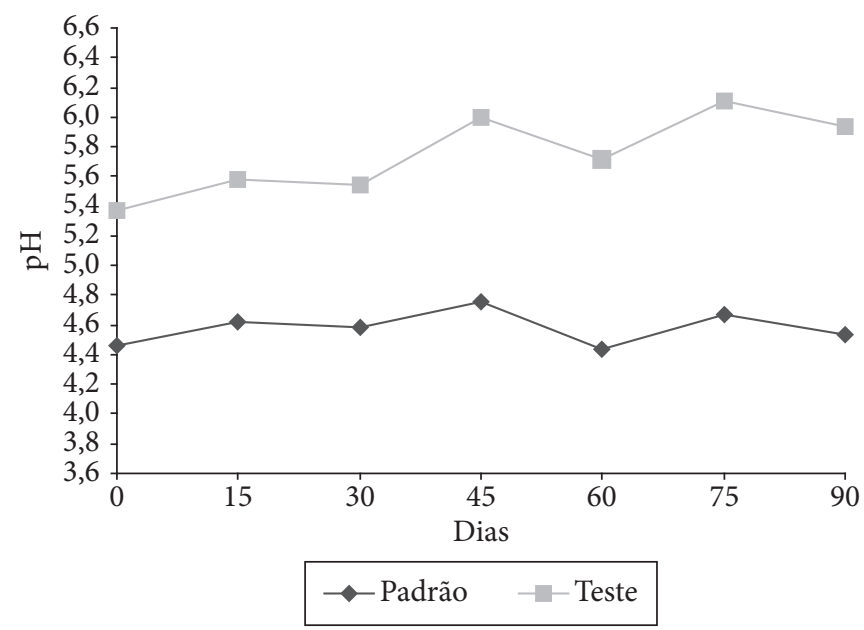

Figura 2. Resultados preliminares de $\mathrm{pH}$ nos queijos padrão e teste, antes de serem embalados a vácuo e durante 90 dias de armazenamento, a $6{ }^{\circ} \mathrm{C}( \pm 1)$ e UR $85 \%$. 
Compreende-se melhor a influência da não fabricação dos queijos ao mesmo tempo, ao analisarmos os valores iniciais de $\mathrm{pH}$, acidez Dornic e contagem de bactérias ácido lácticas nos leites empregados nas fabricações dos queijos padrão e teste, que se encontram na Tabela 1 . Nela observa-se que o leite empregado na fabricação do queijo padrão apresentou menor valor de $\mathrm{pH}$ e maior valor de acidez Dornic e contagem de bactérias ácido lácticas. Em relação à adição de cultura probiótica, Gobetti et al. (1998) e Stanton et al. (2001) observaram que queijos com probióticos apresentaram maiores valores de $\mathrm{pH}$ em relação aos queijos que não continham probióticos. Relacionaram-se esses maiores valores de $\mathrm{pH}$ com a maior atividade proteolítica verificada.

O queijo prato maturado se caracteriza por apresentar $\mathrm{pH}$ na faixa entre 5,2 a 5,4 (FURTADO; LOURENÇO NETO, 1994). O queijo teste, do $15^{\circ}$ dia de armazenamento em diante, apresentou valores de $\mathrm{pH}$ acima do valor máximo característico de queijo prato. Esses maiores valores estariam relacionados à utilização de leite com baixo teor de gordura $(1,3 \%)$ utilizado na fabricação do queijo (BANKS, 2004) e a adição de cultura probiótica (STANTON et al., 1998; GOBETTI et al., 1998) (Figura 2).

Os resultados preliminares de lactose nos queijos padrão e teste, antes de serem embalados a vácuo e durante 90 dias de armazenamento, a $6{ }^{\circ} \mathrm{C}( \pm 1)$ e UR $85 \%$ são apresentados na Figura 3.

No queijo teste os resultados preliminares de lactose variaram de 4,29\% (antes de ser embalado a vácuo) a $0,45 \%$ $\left(112^{\circ}\right.$ dia), enquanto que no queijo padrão a variação foi de $3,56 \%$ a zero a partir do $75^{\circ}$ dia. Em todos os dias analisados o queijo teste apresentou maior teor de lactose em relação ao queijo padrão, apresentando diferença significativa pelo teste de Tukey $(\mathrm{p}<0,05)$ (Figura 3).

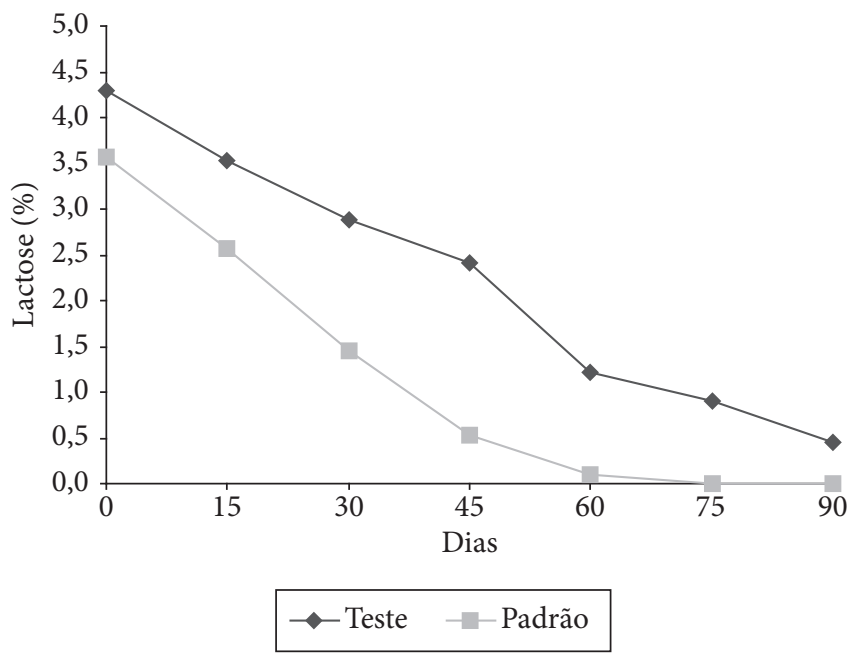

Figura 3. Resultados preliminares de lactose nos queijos padrão e teste, antes de serem embalados a vácuo e durante 90 dias de armazenamento, a $6{ }^{\circ} \mathrm{C}( \pm 1)$ e UR $85 \%$.
Corcoran et al., (2005) observaram que o Lactobacillus rhamnosus não metabolizava bem a lactose em $\mathrm{pH} 5,84$. Isso pode ter ocorrido no queijo teste, pois os valores de $\mathrm{pH}$ (Figura 2) do $15^{\circ}$ dia em diante situaram-se perto de 5,84, os quais influenciaram o metabolismo do Lactobacillus rhamnosus, e como conseqüência os teores de lactose foram maiores do que o queijo padrão (Figura 3).

Os resultados preliminares de acidez Dornic nos queijos padrão e teste, antes de serem embalados a vácuo e durante 90 dias de armazenamento, a $6{ }^{\circ} \mathrm{C}( \pm 1)$ e UR $85 \%$ são apresentados na Figura 4.

O queijo teste apresentou menores valores preliminares de acidez em relação aos valores encontrados no queijo padrão, ocorrendo diferença significativa em todos os dias analisados, pelo teste de Tukey $(\mathrm{p}<0,05)$. Essa menor acidez ocorrida no queijo teste vem em concordância com os resultados preliminares de $\mathrm{pH}$ e lactose apresentados nas Figuras 2 e 3, respectivamente.

Queijos light embalados a vácuo e maturados a $13{ }^{\circ} \mathrm{C} \mathrm{e}$ 80\% UR, após 30 e 48 dias de armazenamento, apresentaram valores de acidez de 1,33 e 1,23\%, respectivamente (SILVA et al., 2005). O queijo teste que também foi embalado a vácuo, mas armazenado a $6{ }^{\circ} \mathrm{C}$, apresentou valor de acidez dentro dessa faixa somente no $112^{\circ}$ dia de armazenamento. Essa menor acidez encontrada no queijo teste (Figura 4) seria decorrente da menor temperatura de maturação empregada, associada à baixa capacidade de desdobramento da lactose pelo Lactobacillus rhamnosus em pH 5,84 (CORCORAN et al., 2005), uma vez que o queijo teste apresentou valores de $\mathrm{pH}$ bem próximos a esse valor (Figura 2).

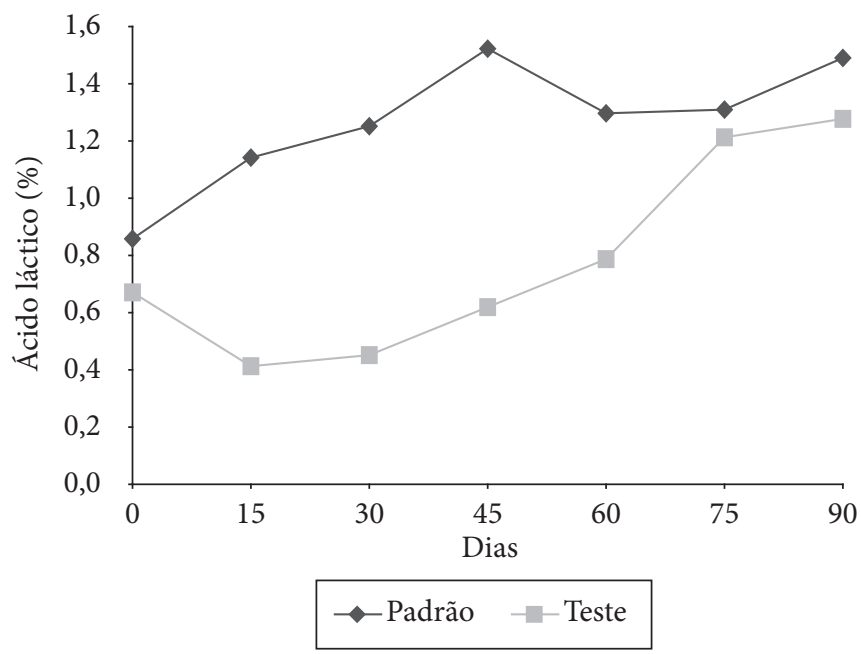

Figura 4. Resultados preliminares de acidez Dornic nos queijos padrão e teste, antes de serem embalados a vácuo e durante 90 dias de armazenamento, a $6{ }^{\circ} \mathrm{C}( \pm 1)$ e UR $85 \%$. 


\section{Conclusões}

No queijo com adição de cultura probiótica ocorreu melhor desenvolvimento das bactérias ácido lácticas, maiores valores de $\mathrm{pH}$ e lactose, e baixa acidez.

\section{Referências bibliográficas}

ALANDER, M. et al. Persistence of colonization of human colonic mucosa by a probiotic strain, Lactobacillus rhamnosus GG, after oral consumption. Applied and Environmental Microbiology, Washington, USA, v. 65, n. 1, p. 351-354, 1999.

BANKS, J. M. The technology of low-fat cheese manufacture. International journal of Dairy Technology, Huntingdon, v. 57, n. 4, p. 199-207, 2004.

BELCHIOR, F. O ingrediente do lácteo saudável. Leite e Derivados, São Paulo, v. 13, n. 76, p. 54-64, 2004.

BRASIL. Ministério da Agricultura, Pecuária e Abastecimento. Regulamento Técnico de Identidade e Qualidade do Queijo Prato. Portaria 358, 04 set. 1997.

. Instrução normativa 51, 18 set. 2002, Revoga Portaria n. 146, 7 mar. 1996. Regulamentos técnicos de identidade e qualidade de produtos lácteos. Diário Oficial da União, Brasília, 20 set. 2002.

BURITI, F. C. A. Desenvolvimento de queijo fresco cremoso simbiótico. São Paulo, 2005. 86 p. Dissertação (Programa de PósGraduação em Tecnologia Bioquímico-Farmacêutica, Área de Tecnologia de Alimentos) - Universidade de São Paulo (USP).

CAMPOS, G. H. Estatística experimental não paramétrica. 4. ed. Piracicaba, São Paulo: ESALQ, 1983, 349p.

CORCORAN, B. M. et al. Survival of probiotic Lactobacilli in acidic environments is enhanced in the presence of metabolizable sugars. Applied and Environmental Microbiology, Washington, USA, v. 71, n. 6, p. 3060-3067, 2005.

FURTADO, M. M.; LOURENÇO NETO, J. P. M. Tecnologia de queijos: Manual técnico para a produção industrial de queijos. São Paulo: Dipemar, 1994. p. 91-92.

FURTADO, M. M. A formação de olhaduras em queijos semiduros através da fermentação de citratos. Revista indústria de laticínios, São Paulo, p. 32-39, jul./ago. 2002.

GOBETTI, M. et al. Production of Crescenza Cheese by incorporation of bifidobacteria. Journal of Dairy Science, Sauoy, IL, v. 81, n. 1, p. 37-47, 1998.

GORBACH, S. L. Probiotics in the third millennium. Digestive and Liver Disease, Milan, Italy, v. 34, n. 2, p. 2-7, 2002.

IAL - Instituto Adolfo Lutz. Métodos físico-químicos para análises de alimentos. 4. ed. São Paulo: Instituto Aldolfo Lutz, 2005. 1018p.

INTERNATIONAL DAIRY FEDERATION (FIL-IDF) Standard 28A. Determination of the lactose content of cheese and processed cheese products. Brussels, 1974.

ISOLAURI, E. et al. Probiotics: effects on immunity. The American Journal of Clinical Nutrition, Houston, USA, v. 73, n. 3, p. 444-450, 2001.
KAPLAN, N. M. The dietary guideline for sodium: should we shake it up? No. The American Journal of Clinical Nutrition, Houston, USA, v. 71, n. 6, p. 1020-1026, 2000.

KATSIARI, M. C. et al. Manufacture of Kefalograviera cheese with less sodium by partial replacement of $\mathrm{NaCl}$ with $\mathrm{KCl}$. Food Chemistry, Reading, UK, v. 61, n. 1/2, p. 63-70, 1998.

KASIMOGLU, A.; GÖNCÜOGLU, M.; AKGÜN, S. Probiotic white cheese with Lactobacillus acidophilus. International Dairy Journal, Reading, UK, v. 14, n. 12, p. 1067-1073, 2004.

LANDERSJÖ, C. et al. Structural studies of the exopolysaccharide produced by Lactobacillus rhamnosus strain GG (ATCC 53103). Biomacromolecules, Washington, USA, v. 3, n. 4, p. 880-884, 2002.

OHR, L M. Improving the gut feeling. FoodTechnology, Chigaco, IL, v. 56, n. 10 , p. $67-70,2002$.

SALMINEN, S.; OUWEHAND, A. C.; ISOLAURI, E. Clinical applications of probiotic bacteria. International Dairy Journal, Reading, UK, v. 8, n. 5, p. 563-572. 1998.

SILVA, B. R. C. et al. Maturação de queijo prato: comparação entre o produto integral e o produzido com teor reduzido de gordura. Anais do XXII Congresso Nacional de Laticínios, 2005, Juiz de Fora - MG. Anais... Juiz de Fora - MG: Taylor e Francis, 2005. p. 235-238.

SILVA, N.; JUNQUERIA, V. C. A.; SILVEIRA, N. F. A. Manual de Métodos de Análise Microbiológica de Alimentos. São Paulo: Livraria Varela, 1997. 295p.

DA SILVEIRA, P. R.; DE ABREU, L. R. Rendimento e composição físico-química do queijo prato elaborado com leite pasteurizado pelo sistema HTST e injeção direta de vapor. Ciência Agrotécnica de Lavras, Lavras, MG, v. 27, n. 6, p. 1340 - 1347, 2003.

SONGISEPP, E. et al. A new probiotic cheese with antioxidative and antimicrobial activity. Journal of Dairy Science, Sauoy, IL, v. 87, n. 7, p. 2017-2023, 2004.

STANTON, C. et al. Probiotic cheese. International Dairy Journal, Reading, UK, v. 8, n. 5, p. 491-496, 1998.

STANTON, C. et al. Market potential for probiotics. The American Journal of Clinical Nutrition, Houston, USA, v. 73, n. 3, p. 476-483, 2001.

TUNGLAND, B. C. Inulin: A comprehensive scientific review. Disponível em: <http:// members.shaw.ca/duncancrow/inulin_ review.html>. Acesso em: 25 ago. 2005.

VAN DENDER, A. G. F.; BOSI, M. G.; CONRADO, P. B. Fibra alimentar e a sua utilização na fabricação de produtos lácteos funcionais. Leite e Derivados, São Paulo, v. 14, n. 82, p. 107-115, 2005.

VARNAM, A. H.; SUTHERLAND, J. P. Queso In: Leche y productos lácteos. Espanha: Editorial Acribia, S.A. Zaragoza 1995. p. 291-364.

ZALAZAR, C. A. et al. Probiotic bactéria as adjunct starters: influence of the addition methodology on their survival in a semi-hard Argentinean cheese. Food Research International, Ontario, Canada, v. 38, n. 8, p. 597-604, 2004. 